\title{
Сельцова Ю.В.
}

\section{Конверсионный способ словообразования компьютерной терминологии}

МБОУ СОШ №20

(Россия, Путилково)

doi: 10.18411/scienceconf-03-2021-46

idsp: scienceconf-03-2021-46

\section{Аннотация}

В статье автор рассматривает группу терминов из словаря компьютерной лексики с целью поиска компьютерных терминов, образовавшихся путем конверсии. Быстрое развитие компьютерных технологий, их внедрение во все сферы нашей жизни породили новую терминологическую систему, во многом опережающую специальную лексику других отраслей науки и техники по темпам ее развития и распространения. Конверсия является типичным явлением для многих функциональных стилей английского языка, включая языки для специальных целей, а именно терминологии различных отраслей науки и техники.

Ключевые слова: лингвистика, лексикология, словообразование, английский язык, компьютерная терминология, конверсия.

\section{Abstract}

The author considers the group of terms from «Dictionary of IBM and computing terminology» in order to find computer terms formed by conversion. Rapid development in computer technology has created a new system of terms that shows a high-paced growth in the development and dissemination. Conversion is a typical phenomenon for many functional styles of the English language including the terminology of different sectors of science and technology.

Компьютерная терминология как часть специальной лексики компьютерного языка - одна из новейших областей специального знания, наравне с кибернетикой, робототехникой, бионикой и др. Ведущим процессом в развитии словарного состава английского языка на всех его этапах было словопроизводство, то есть образование новых слов из наличествующего материала с помощью тех словообразовательных средств, которые сложились в языке. В данной статье наиболее подробно остановимся на конверсии. Суть конверсии как словообразовательного процесса состоит в том, что происходит функциональный сдвиг слова из одной частеречной категории в другую, образование одной части речи от основы другой без изменения формы. Например: buffer, $n \rightarrow$ to buffer, $v$; bullet, $n \rightarrow$ to bullets, $v$.

В конверсионных отношениях могут находиться слова любой части речи. Выделяются десять моделей конверсии:

1. существительное $\rightarrow$ глагол;

2. прилагательное $\rightarrow$ глагол (а также наречие, междометие $\rightarrow$ глагол);

3. глагол $\rightarrow$ существительное;

4. прилагательное $\rightarrow$ существительное;

5. существительное $\rightarrow$ прилагательное;

6. наречие $\rightarrow$ существительное (а также междометие $\rightarrow$ существительное);

7. наречие $\rightarrow$ прилагательное;

8. глагол $\rightarrow$ прилагательное;

9. глагол $\rightarrow$ наречие;

10. местоимение / числительное $\rightarrow$ глагол.

Следует отметить, что не все модели конверсии одинаково активны и продуктивны; кроме того, степень их активности и продуктивности различна в разные периоды развития английского языка. В настоящее время в наибольшей степени 
продуктивны процессы образования отыменных глаголов $(\mathrm{N} \rightarrow \mathrm{V})$ и отглагольных существительных $(\mathrm{V} \rightarrow \mathrm{N})$; менее активными моделями являются субстантивация прилагательных (Adj $\rightarrow \mathrm{N}$ ) и адъективация существительных $(\mathrm{N} \rightarrow \mathrm{Adj})$ [1].

1. Модель $\mathbf{N} \rightarrow \mathbf{V}$ (существительное $\rightarrow$ глагол) - самая продуктивная модель конверсии. По мнению Г. Марчанда высокий уровень активности можно объяснить тем, что в английском в отличие от некоторых других языков нет другого продуктивного способа образования глаголов от существительных. Единственными словообразовательными морфемами для образования отглагольных существительных в современном английском языке можно назвать суффиксы -ize, -ate, -ity, но чаще всего их присоединяют к основам латинских слов, чтобы получить научно-технические термины. Поэтому, в языке возникла потребность в дополнительном способе создания глаголов [4]. Были обнаружены следующие глаголы, образованные по данной модели: cache, $n \rightarrow$ to cache, $v$; catalog, $n \rightarrow$ to catalog, $v$; checkpoint, $n \rightarrow$ to checkpoint, $v$; delta, $n$ $\rightarrow$ to delta, $v$; demo, $n \rightarrow$ to demo, $v$; display, $n \rightarrow$ display, $v ;$ fax, $n \rightarrow$ to fax, $v$; flag, $n \rightarrow$ to flag, v; green sheet, $n \rightarrow$ to green sheet, v; host, $n \rightarrow$ to host, $v ;$ hot key, $n \rightarrow$ to hot key, $v$; interface, $n \rightarrow$ to interface, $n$; link, $n \rightarrow$ to link, $v ;$ mask, $n \rightarrow$ to mask, $v$; microcode, $n \rightarrow$ to microcode, $v$; monitor, $n \rightarrow$ to monitor, $v$; pipeline, $n \rightarrow$ to pipeline, $v$; pitch, $n \rightarrow$ to pitch, $v$; port, $n \rightarrow$ to port, v; post, $n \rightarrow$ to post, v; process, $n \rightarrow$ to process, $v$; program, $n \rightarrow$ to program, v; queue, $n \rightarrow$ to queue, v; spooling, $n \rightarrow$ to spool, $v$.

Глагольные неологизмы, образованные по этой модели конверсии input, $\mathrm{n} \rightarrow$ input, v. - вводить данные (в машину); servo, $\mathrm{n} \rightarrow$ servo, $\mathrm{v}$ - дистанционно управлять, не имеют однословных соответствий в русском языке. При вербализации соответствующих субстантивных компьютерных терминов имеет место минизация семантических ролей, как в уже упоминавшихся, например: to cache, $v$ - to place in a cache; to catalog, $v$ - to enter the information about a file into a catalog; to process, $v$ - to perfom operations on data in a process.

Следовательно, характерной чертой английской конверсии, в частности, и в первую очередь конверсии $\mathrm{N} \rightarrow \mathrm{V}$, является большая свобода семантических отношений. По существу, при конверсии $\mathrm{N} \rightarrow \mathrm{V}$ могут устанавливаться любые смысловые отношения между исходным именем существительным и глаголом [3].

2. Модель Adj $\rightarrow \mathrm{V}$ (прилагательное $\rightarrow$ глагол; реже наречие, междометие $\rightarrow$ глагол). В современном английском языке модель $\mathrm{Adj} \rightarrow \mathrm{V}$ не считается продуктивной. По этой модели отмечаются только отдельные случаи образования неологизмов, например: fail-safe, adj - (техн.) надежный, работающий без сбоев $\rightarrow$ fail-safe, v, - (техн.) автоматически устранять повреждения, устанавливать аппаратуру для автоматического устранения повреждений.

Неологизмов общелитературного языка, созданных по этой модели, довольно мало, и большинство из них относятся к сленгу: whee, int - вот это здорово! Ура! $\rightarrow$ whee, (whee up), v - подбадривать. Компьютерных терминов, созданных по этой модели, в нашем материале нет.

3. Модель $\mathbf{V} \rightarrow \mathbf{N}$ (глагол $\rightarrow$ существительное). Данная модель по активности уступает лишь модели $\mathrm{N} \rightarrow \mathrm{V}$. Существует мнение, что это можно объяснить тем, что существуют и другие способы создания отглагольных существительных (например, суффиксальные — organization). В настоящее время в английском языке количество отглагольных существительных довольно велико (look смотреть - look- взгляд, knock-стучать - knock-стук). Также существует особенная группа существительных, образованных с помощью конверсии от глаголов с постпозитивами (check up- проверять - checkup- проверка, контроль). to allocate, $\mathrm{v} \rightarrow$ allocate, n. В нашем материале к этой группе относятся существительные logoff, logon, rollout/ roll out. 
to dump, $v \rightarrow$ dump, $n$; to interrupt, $v \rightarrow$ interrupt, $n$; to log off, $v \rightarrow \operatorname{logoff,~} n$; to log on, $v \rightarrow$ logon, $n$; to reset, $v \rightarrow$ reset, $n$; to roll out, $v \rightarrow$ rollout, $n$; to time stamp, $v \rightarrow$ time stamp, $n$; to zoom, $v \rightarrow$ zoom, $n$.

Данная конверсионная модель не является особенно продуктивной, как и в компьютерной терминологии, так и в английском языке в целом. Также можно сделать вывод, что при конверсии по данной модели, чаще всего используются простые и аффиксальные производные основы.

4. Модель $\mathrm{Adj} \rightarrow \mathbf{N}$ (прилагательное $\rightarrow$ существительное). В нашем материале не встречается.

5. Модель $\mathbf{N} \rightarrow \mathbf{A d j} \quad$ (существительное $\rightarrow$ прилагательное). Существительные в английском языке довольно часто употребляются в качестве определения другого существительного, поэтому, можно сказать, что эта тенденция не ведет к образованию новых лексических единиц. Единственный пример, да и то довольно сомнительный, в нашем словаре: key, $\mathrm{n} \rightarrow \mathrm{key}, \mathrm{adj}$

Но все же бывают случаи, когда существительное приобретает лексикограмматические признаки прилагательного. Например: look-ahead — человек обладающий способностью компьютера понять или просчитать дальнейшие возможности или шаги. Стоит отметить, что в данном примере конверсия сочетается с другим способом словообразования, а именно со словосложением.

6. Модели наречие $\rightarrow$ существительное, наречие $\rightarrow$ прилагательное, глагол $\rightarrow$ прилагательное, глагол $\rightarrow$ наречие. Данные модели не являются продуктивными.

Можно согласиться с В.И. Заботкиной, которая полагает, что конверсия как способ создания новых слов путем деривации в настоящее время менее активна и уступает всем другим видам словообразования [2]. По ее мнению, основной моделью остается $\mathrm{N} \rightarrow \mathbf{V}$, по которой образуется большое количество новых терминов (page, $\mathrm{n} \rightarrow$ to page, v). Довольно много глаголов образуется от сложных существительных (checkpoint, $\mathrm{n} \rightarrow$ to checkpoint, $\mathrm{v}$ ).

Образование существительных от глаголов в настоящее время остается менее активным. Это можно объяснить тем, что в английском языке существительные легко образуются от глаголов путем аффиксации. Также, стоит отметить, что увеличилось количество существительных, образованных путем конверсии от глаголов с послелогами (to sign on, $\mathrm{v} \rightarrow$ sign-on, n). Проявляет активность и модель $\mathrm{N} \rightarrow$ Adj (key, $\mathrm{n}$ $\rightarrow$ key, adj).

Давая описание словам, образованных путем конверсии, можно исходить из их структурных моделей (структурная классификация), или из их значений (семантическая классификация). При структурной классификации анализируется морфемный состав исследуемых слов. В основном в конверсии терминов участвуют простые (непроизводные) основы, но вследствие возрастающей активности данного способа словообразования, в конверсии также участвуют аффиксальные производные, сложные слова, сокращения и словосочетания.

1. Простые (корневые, непроизводные) основы имеют только одну составляющую - корень - и отличаются своей неделимостью. От таких основ часто образуются именные глаголы (to cache, v - to place, hide or store in a cache) или деадъективные существительные (субстантивация) (open, $\mathrm{n}$ - a break in an electrical circuit).

2. Аффиксальные производные основы. Такие основы являются вторичными единицами и отличаются наличием префикса или суффикса. Производящими при конверсии могут выступать и префиксальные и суффиксальные основы. Примерами конверсии от префиксальных основ, могут быть слова, образованные по модели 
- $\quad \mathrm{V} \rightarrow \mathrm{N}$ или, другими словами, отглагольные существительные (update модернизация, обновление данных)

- $\quad \mathrm{Adj} \rightarrow \mathrm{V}$ или деадъективные глаголы (uplevel, adj — a more recent version of a program or document; $\rightarrow$ to uplevel, $\mathrm{v}$ - to install a more recent version of a program or document)

- $\quad \mathrm{N} \rightarrow \mathrm{V}$ или отыменные глаголы (position, $\mathrm{n}$ - a point of view or attitude on a certain question $\rightarrow$ to position, $\mathrm{v}$ - to explain or provide context)

3. Производные основы-сокращения. Производными основами при конверсии часто служат такие лексические единицы, которые являются следствием сокращения (усечения, аббревиация, телескопия). Например: spooling, n (simultaneous peripheral operationonline) $\rightarrow$ to spooling, v. Аббревиатуры также используются в качестве исходных основ.

4. Сложные основы. В последнее время проявляют активность модели конверсии в сфере сложных слов, а особенно модель $\mathrm{V} \rightarrow \mathrm{N}$. Примерами этому могут служить:

- $\quad$ именные основы структурного типа «основа существительного + основа существительного» (point to point, adj — pertaining to data transmission between two locations without the use of any intermediate display or computer);

- $\quad$ именные основы структурного типа «основа прилагательного + основа существительного» (to green sheet, $\mathrm{v}$ - to submit an expense for repayment);

- «основа глагола + основа существительного» (to checkpoint, $\mathrm{v}$ - to record the information about a status of a program's execution).

5. Словопроизводящие словосочетания. Build-to-order, adj — of a hardware product: manufactures or to be manufactured, following customer orders;

Проведя наше исследование, мы выявили, что наибольшую активность при словообразовании путем конверсии в компьютерной терминологии проявляют простые и аффиксальные производные основы.

$$
* * *
$$

1. Бортничук Е.Н., Василенко И.В., Пастушенко Л.П. Словообразование в современном английском языке. - Киев, 1988.

2. Заботкина В.И. Новая лексика современного английского языка. - М., 1989.

3. Пьянзина И. Н. Основы лексикологии английского языка. - Нижний Новгород, 2005.

4. Marchand H. Expansion, transposition and -derivation / H. Marchand // La Linguistique. - 1967. - Vol. 7. - P. $13-26$.

\section{Selezneva O.N. \\ Present Indefinite, Present Continuous in expressing the future tense in the modern English language}

Tver branch of RANEPA

(Russia, Tver)

doi: 10.18411/scienceconf-03-2021-47

idsp: scienceconf-03-2021-47

\section{Аннотация}

В статье поднимается вопрос о толковании значений презентных форм, а именно Present Indefinite, Present Continuous, в обозначении будущего времени в современном английском языке. Презентные формы являются одним из популярных средств выражения будущего, начиная с древнеанглийского и до настоящего времени. Автор статьи предполагает, что в современном английском языке презентные формы 